\title{
Synergic Impact of Inhibitors of Cloud Computing --FISM and FMICMAC Approach
}

\author{
Ambika Devi Amma.T \\ Research Scholar Karpagam \\ University. (Professor, Dept .of \\ Computer Science \&Engg, NSS \\ College of Engineering, Palakkad, \\ Kerala, India 678008
}

\author{
Radhika.N, Ph.D \\ Associate Professor, \\ Computer Science \& Engg Dept, \\ Amrita University, Coimbatore, \\ TamilNadu, India 641105
}

\author{
Pramod.V.R, Ph.D \\ Associate. Professor, Dept. \\ of Mechanical Engineering, \\ NSS College of Engg, \\ Palakkad, Kerala, India \\ 678008
}

\begin{abstract}
Cloud services enable continent on demand network access to a shared pool of configurable computing resources. Data migration within cloud is complicated. Cloud computing strategy is subjected to many inhibitors. This paper deals with the deployment of Fuzzy Interpretive Structural Modeling (FISM) to model the interrelationships among the inhibitors of cloud computing. The model is made based on SSIM, Fuzzy initial reachability matrix, fuzzy final reachability matrix and stagnation matrix. From MICMAC analysis the most sensitive inhibitors are identified.
\end{abstract}

\section{Keywords}

Fuzzy ISM, MICMAC, Cloud, inhibitors.

\section{INTRODUCTION}

The major risks are the deterioration of customer care and service quality decreasing job satisfaction of support engineers sales marketing staff, departmental downs sizing and uncertainty with new technology. Due to simple, apparent, cheap and scalable nature cloud computing is deployed in IT system. Data migration within cloud storage is complicated due to cloud scaling. In data migration the optimization is in scaling speeds. Scalability is the main reason for using cloud computing paradigm. Relocation of huge chunks of data simultaneously causes a drastic degradation in performance. Storage cloud is based on infrastructure as a service. Storage cloud is able to change number storage devices.

The main characteristic of cloud computing is that datas are hosted by cloud service providers, Data security must be strongly considered in cloud. The performance of cloud depends on privacy requirement and data encryption. Privacy is very much important in e-commerce applications. Identification, authorization of data like password, user right etc are critical for ensuring authenticity of users and proper access to resources. Information security and privacy concerns cloud service use in business critical applications. Cloud services enable convenient on demand network access to a shared pool of configurable computing resources that can be rapidly provisional and released with minimal management effort or service providers' interaction. Privacy measurement can be carried out by service providers. Cloud service providers should publish different kind of reports concerning how personal data handling is done how errors are handled. Privacy awareness of quality and quantity of the end users can be measured. Cloud storage systems have hundreds of data servers. Same information may be stored in multiple machines.
Different power supply may also be used to keep redundancy. Workload aware scheduling algorithm can improve storage migration performances. In cloud computing third party stores data for the data owner. Third party provides both storage capacity and processing capacity. The chief issue regarding is integrity and safety of data. Once the organizations data is moved to the cloud data control is lost by the organization i.e. the data is controlled by the third party in cloud. Cloud computing can facilitate the flow of information between the outsourced service and the outsourcing service.

The aim of this paper is to develop relationship among the major inhibitors of cloud computing using FISM. MICMAC analysis is done on inhibitors based on their driving power and dependence power. The inhibitors are classified into different categories. The objective of the study requires qualitative data. Various inhibitors of the services and qualitative data are identified based on literature survey and discussion with experts. The major inhibitors are given below

Table 1.Major Inhibitors of Cloud Computing

\begin{tabular}{|l|l|l|}
\hline Inhibitors & Major Inhibitors of Cloud Computing & \multicolumn{1}{|c|}{ References } \\
\hline 1 & Lack of sufficient security & {$[1],[2],[4],[6],[7]$} \\
\hline 2 & Lack of reliability & {$[1],[2],[4],[6],[7]$} \\
\hline 3 & Lack of portability & {$[1],[2],[18]$} \\
\hline 4 & Lack of privacy & {$[1],[2],[18]$} \\
\hline 5 & Lack of standardization & {$[1],[2],[18]$} \\
\hline 6 & Lack of comprehensive management & {$[1],[2],[18]$} \\
\hline 7 & Weak access control & {$[1],[2],[18]$} \\
\hline 8 & Lack of data confidentiality & {$[1],[2],[18]$} \\
\hline 9 & Ineffective back up management & {$[1],[2],[18]$} \\
\hline 10 & Cost/ time barrier & {$[1],[2],[18]$} \\
\hline 11 & Network management barrier & {$[1],[2],[18]$} \\
\hline 12 & Legal issues & {$[1],[2],[18]$} \\
\hline 13 & Infrastructure security -at network level & {$[1],[2],[18]$} \\
\hline 14 & Infrastructure security -at host level & {$[1],[2],[18]$} \\
\hline 15 & Infrastructure security -application level & {$[1],[2],[18]$} \\
\hline 16 & Data security & {$[1],[2],[18]$} \\
\hline 17 & Data integrity & {$[1],[2],[18]$} \\
\hline 18 & Data availability & {$[1],[2],[18]$} \\
\hline & &
\end{tabular}


In order to increase the readability of the article, a brief enumeration of the term is given below.

1. Lack of sufficient security: It is related to the security concern of the cloud services. Security should include browser security also.2. Lack of reliability: The customer should feel that the services done by the cloud service provider is reliable in the sense the data's attaining from the cloud is correct. It is not assured.3. Lack of portability: The data stored in one country can be transferred to another data center in another country. A pointed violation of local law may result. 4. Lack of privacy: Privacy is the accountability to data and transparency to an organizations practice about personal information. 5. Lack of standardization: Standards are source within the cloud mass adoption is difficult without standards. 6. Lack of comprehensive tools management: These tools would help automatic server providing and aids with capacity planning and configuration management. 7. Week access control: The ability to manage the infrastructure is weak more control to manage servers, networking and cabling are weak. 8. Lack of data confidentiality: Authorization and authentication relate to confidentiality. Confidentiality depends on how data put into the cloud will be secure and available.

9. Ineffective backup management: Lack of how effective backup of data. 10. Cost/time management: Cost/time barrier should be evaluated closely as a cloud migration. 11. Network Management: Cloud services are done through internet world wide web. Managing the network is a tedious process. 12. Legal issues: Cloud data migration from one country to another face legal issue. 13. Infrastructure Security: -In network level - Network topology should be changed according to the security requirement. 14. Infrastructure Security: In host level, depends on the delivery models like SaaS, PaaS, IaaS and deployment models like private, public and hybrid. 15. Infrastructure Security: In application level-depends on the revolution of current practices and security in application. 16. Data Security: Data should be protected without making any processing on it. 17. Data Integrity: What a customer wants to do is to validate the integrity of data while that data remains in the cloud. 18. Data availability: Data should be available for the customer at their needs, highly available database form is more complex.

\section{LITERATURE SURVEY}

Cloud computing is facing many issues. Security issues of cloud computing is very large .Privacy is one of the most important issue $[1,2,3]$. The laws regarding privacy are different in different countries [1]. Multiple jurisdictions are existing for clouds [1,8, and 9]. Computing resources are provided as public utility and can be used anywhere at anytime. Cloud computing support cloud manufacturing which is a service oriented network manufacturing paradigm. Service Oriented Architecture and utility computing provides manufacturing services on demand according to the requirement of end user through internet.
Production oriented manufacturing system is completely turned into service oriented system [Quan Liu, Lu Gao, Ping Lou, 2011]. Policy issues in cloud computing technology are privacy, security, anonymity, government surveillance, reliability, availability etc. Most of the users may be using the same virtual machine and if somebody hack and take control over it he will be able to access the whole data within the machine. The hacker may copy the content of the virtual machine before detecting out of control of that virtual machine by the cloud service providers [Farzad Sabatri, 2011]. Many risks of internet is faced by cloud computing and one of the most powerful attack facing by cloud is the distributed denial of service.

Cloud computing services are effected by data access and interoperability [Craig A LEE].Rapid growth in information technology in rural area is provided by cloud computing, Cloud computing has wide field of applications. The cloud infrastructure consists of large number of parallel servers operated in distributed networking environment using virtualization technology. For developing user friendly programs many application programming interfaces are used to run software as a service mode. [Peirisc, Sharma. D-2011].The computing resources are managed automatically through software virtualization. Efficiently all CPU resources are shared and distributed as if a single server environment. Evolution of cloud computing is affected by the regulatory laws and order. A set of major security and privacy risk is created by cloud computing services paradigms. These issues can harm the cloud service. [Reijoo M Savola2010 IEEE]. For studying the interrelationship of variables affecting any system, interpretive structural modeling has been used for past twenty five years. This methodology is dealing with complex issues. It is considered as a computer assisted learning process [Sage A1977] [J.Warfield-1973]. In fuzzy ISM fuzzy logic is used to describe fuzziness. Fuzzy set theory resembles human reasoning in its use of approximate information and uncertainty to generate decision. Fuzzy logic is specifically designed to mathematically represent uncertainty and vagueness and provide formalized tools for dealing with the imprecision intrinsic to many problems. Many engineering and decision problems can be greatly simplified. Fuzzy logic is a set of mathematical principles for knowledge representation based on degrees of membership. Unlike two valued Boolean logic i.e. true or false ( 0 or 1 ) fuzzy logic is multivalued. It deals with degrees of membership and degrees of truth. Fuzzy logic uses the continuum of logical values between 0 (completely false) and 1 (completely true).

\section{METHODOLOGY}

Fuzzy ISM is an advanced methodology compared to ISM. ISM is a learning process for finding the inter relationship between variables of a system. ISM has predefined steps for achieving the results. For obtaining the interrelationship among the variables ISM uses binary number 0 and 1.0 is used for no relation and 1 for having the relation. In fuzzy 
ISM an additional input of possibility of interaction is on 0 1 scale avoiding $0 \& 1$.

\subsection{Development of fuzzy ISM}

Based on contextual relationship among inhibitors a structural self interaction matrix is developed A pair-wise relationship among the inhibitors are carried out. Assuming $i \& \mathrm{j}$ are the element then the symbol $\mathrm{V}$ denotes that $\mathrm{i}$ will help to achieve $\mathrm{j}$. The symbol A denotes that $\mathrm{j}$ will help to achieve i. The symbol X means i \& j will help each other to achieve. O means $\mathrm{i} \& \mathrm{j}$ are unrelated. Structural self interaction matrix is shown in Table 2

Table2. Structural Self Interaction Matrix (SSIM)

\begin{tabular}{|c|c|c|c|c|c|c|c|c|c|c|c|c|c|c|c|c|c|c|}
\hline & & 18 & 17 & 16 & 15 & 14 & 13 & \begin{tabular}{|l|}
12 \\
\end{tabular} & \begin{tabular}{|l|}
11 \\
\end{tabular} & 10 & 9 & 8 & 7 & 6 & 5 & 4 & & 2 \\
\hline 1 & \begin{tabular}{|l} 
Lack of sufficient \\
\end{tabular} & $\mathrm{v}$ & \begin{tabular}{|c|}
$\mathrm{v}$ \\
\end{tabular} & $\mathrm{v}$ & $\mathrm{A}$ & \begin{tabular}{|l|l|}
$\mathrm{V}$ \\
\end{tabular} & $\mathrm{v}$ & 0 & \begin{tabular}{|l|l}
$\mathrm{v}$ \\
\end{tabular} & 0 & $\mathrm{~A}$ & $\mathrm{v}$ & $\mathrm{v}$ & 0 & 0 & $\mathrm{~A}$ & 0 & $\mathrm{v}$ \\
\hline 2 & \begin{tabular}{|l} 
Lack of reliability \\
\end{tabular} & $\mathrm{v}$ & \begin{tabular}{|l|l|l|}
$\mathrm{v}$ \\
\end{tabular} & $\mathrm{v}$ & $\mathrm{A}$ & \begin{tabular}{|l|}
$\mathrm{A}$ \\
\end{tabular} & $\mathrm{A}$ & \begin{tabular}{|l|}
$\mathrm{V}$ \\
\end{tabular} & $\mathrm{v}$ & 0 & $\mathrm{~A}$ & $\mathrm{v}$ & 0 & $\mathrm{~A}$ & $\mathrm{v}$ & 0 & 0 & \\
\hline 3 & \begin{tabular}{|l} 
Lack of portability \\
\end{tabular} & $\mathrm{v}$ & \begin{tabular}{|l|ll}
$\mathrm{v}$ \\
\end{tabular} & 0 & \begin{tabular}{|l|l|}
0 \\
\end{tabular} & \begin{tabular}{|l|l|}
0 \\
\end{tabular} & 0 & \begin{tabular}{|l|}
$\mathrm{V}$ \\
\end{tabular} & $\mathrm{v}$ & $\mathrm{A}$ & 0 & 0 & 0 & 0 & $\mathrm{~A}$ & 0 & & \\
\hline 4 & Lack of Privacy & $\mathrm{v}$ & $\mathrm{v}$ & $\mathrm{v}$ & 0 & \begin{tabular}{|l|l|}
0 \\
\end{tabular} & \begin{tabular}{|l|l|}
0 \\
\end{tabular} & $\mathrm{v}$ & 0 & 0 & 0 & $\mathrm{~A}$ & $\mathrm{v}$ & 0 & 0 & & & \\
\hline 5 & Lack of Standardization & $\mathrm{x}$ & \begin{tabular}{|l|l}
$\mathrm{V}$ \\
\end{tabular} & $\mathrm{A}$ & $\mathrm{A}$ & $\mathrm{A}$ & $\mathrm{A}$ & \begin{tabular}{|l|}
$\mathrm{V}$ \\
\end{tabular} & $\mathrm{v}$ & $\mathrm{A}$ & 0 & $\mathrm{v}$ & $\mathrm{A}$ & $x$ & & & & \\
\hline 6 & \begin{tabular}{|l|}
$\begin{array}{l}\text { Lack of comprehensive } \\
\text { management tool }\end{array}$ \\
\end{tabular} & 0 & 0 & 0 & $\mathrm{~A}$ & $\mathrm{~A}$ & $\mathrm{~A}$ & \begin{tabular}{|l|}
0 \\
\end{tabular} & $\mathrm{~A}$ & $\mathrm{~A}$ & 0 & 0 & $\mathrm{~A}$ & & & & & \\
\hline 7 & Weak access control & $\mathrm{v}$ & \begin{tabular}{|l|l|}
$\mathrm{v}$ \\
\end{tabular} & $\mathrm{v}$ & $\mathrm{v}$ & \begin{tabular}{|l|l|}
$\mathrm{v}$ \\
\end{tabular} & $\mathrm{v}$ & \begin{tabular}{|l|}
0 \\
\end{tabular} & 0 & 0 & 0 & $\mathrm{~A}$ & & & & & & \\
\hline 8 & \begin{tabular}{|l|}
$\begin{array}{l}\text { Lack of data } \\
\text { confidentiality }\end{array}$ \\
\end{tabular} & \begin{tabular}{|l|}
$\mathrm{v}$ \\
\end{tabular} & $\mathrm{v}$ & $\mathrm{v}$ & $\mathrm{V}$ & $\mathrm{V}$ & $\mathrm{v}$ & \begin{tabular}{|l|}
0 \\
\end{tabular} & $\mathrm{~A}$ & 0 & 0 & & & & & & & \\
\hline 9 & $\begin{array}{l}\text { In effective backup } \\
\text { management }\end{array}$ & \begin{tabular}{|c|}
$\mathrm{v}$ \\
\end{tabular} & $\mathrm{v}$ & $\mathrm{v}$ & $\mathrm{V}$ & 0 & 0 & \begin{tabular}{|l|}
0 \\
\end{tabular} & 0 & 0 & & & & & & & & \\
\hline 10 & Cost $/$ time barrier & \begin{tabular}{|l|}
$\mathrm{v}$ \\
\end{tabular} & \begin{tabular}{|l|l}
$\mathrm{v}$ \\
\end{tabular} & $\mathrm{v}$ & $\mathrm{v}$ & \begin{tabular}{|l|l|}
0 \\
\end{tabular} & 0 & \begin{tabular}{|l|l|}
$\mathrm{V}$ \\
\end{tabular} & 0 & & & & & & & & & \\
\hline 11 & $\begin{array}{l}\text { Network management } \\
\text { barrier }\end{array}$ & 0 & 0 & 0 & 0 & $\mathrm{v}$ & $\mathrm{v}$ & $\begin{array}{ll}\mathrm{V} \\
\end{array}$ & & & & & & & & & & \\
\hline 12 & Legal is sues & \begin{tabular}{|l|}
$\mathrm{V}$ \\
\end{tabular} & \begin{tabular}{|l|}
$\mathrm{V}$ \\
\end{tabular} & 0 & 0 & 0 & 0 & & & & & & & & & & & \\
\hline 13 & $\begin{array}{l}\text { Infrastructure security } \\
\text { network level }\end{array}$ & \begin{tabular}{|l|}
$\mathrm{V}$ \\
\end{tabular} & $\mathrm{v}$ & $\mathrm{v}$ & $\mathrm{V}$ & $\mathrm{V}$ & & & & & & & & & & & & \\
\hline 14 & \begin{tabular}{|l} 
Infrastructure security - \\
host level
\end{tabular} & $\begin{array}{ll}\mathrm{v} \\
\mathrm{n}\end{array}$ & $\mathrm{V}$ & $\mathrm{v}$ & A & & & & & & & & & & & & & \\
\hline 15 & \begin{tabular}{|l|} 
Infrastructure security \\
-application level
\end{tabular} & $\mathrm{v}$ & \begin{tabular}{|l|l|l}
$\mathrm{V}$ \\
\end{tabular} & $\mathrm{v}$ & & & & & & & & & & & & & & \\
\hline 16 & Data security & $\mathrm{v}$ & \begin{tabular}{|l}
$\mathrm{v}$ \\
\end{tabular} & & & & & & & & & & & & & & & \\
\hline 17 & \begin{tabular}{|l} 
Data Integrity \\
\end{tabular} & $\mathrm{v}$ & & & & & & & & & & & & & & & & \\
\hline 18 & Data availability & & & & & & & & & & & & & & & & & \\
\hline
\end{tabular}

The rules for achieving initial reachability matrix from structural self interaction matrix (SSIM) are

1. If the (i, j) entry in SSIM is V, then (i, j) entry in the adjacency matrix is 1 and (j.i) entry is 0 .

2. If the (i.j) entry in SSIM is A, then (i, j) entry in the adjacency matrix is 0 and (j.i) entry is 1 .

3. If the (i.j) entry in SSIM is $X$, then $(i, j)$ entry in the adjacency matrix is 1 and (j.i) entry is 1 .

4. If the (i.j) entry in SSIM is $O$, then (i, j) entry in the adjacency matrix is 0 and (j.i) entry is 0 .

The initial reachability matrix is constructed based on the above rule and is shown in Table 3. Then final reachability matrix is constructed, instead of using $0 \& 1$ an additional input of $0-1$ scale is introduced avoiding transitivity. Final reachability matrix is shown in Table 4.

Table 3. Initial Reachability matrix

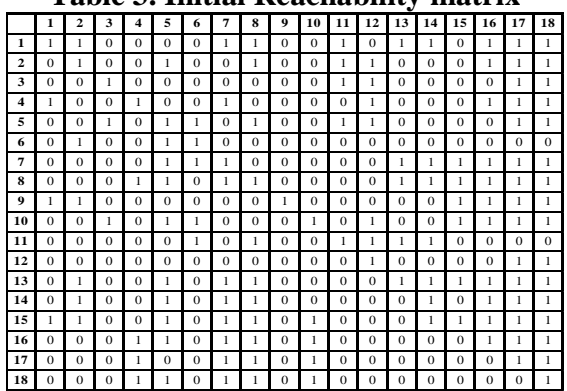

Table4. Final Reachability matrix with driving power and dependence power

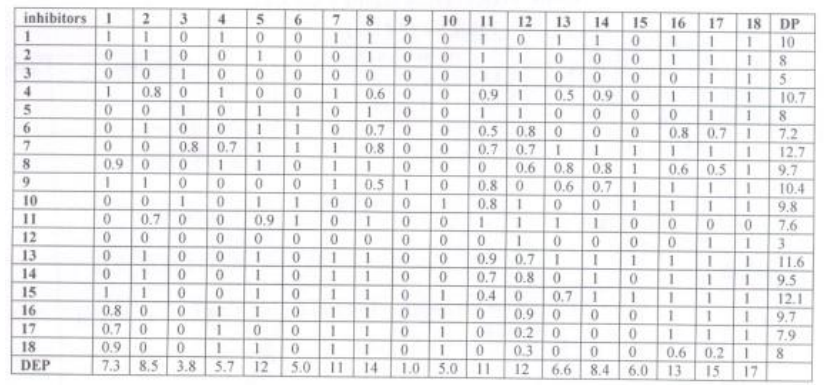

\subsubsection{Level Partitions}

From the final reachability matrix, the reachability and antecedent set for each element is found. The reachability set consists of the elements and other elements which may help to achieve it. The antecedent set consist of the element and other elements which may help in achieving it. After getting reachability set and antecedent set intersection set is derived for all elements. The element for which the reachability and the intersection sets which are same occupy the top level in the ISM hierarchy. The top level element would not help achieve any other element above its own level, The top-level element is separated from other elements. The same process is repeated to find out the next level elements. This process is continued until the level of each element is found. These levels are used for building Fuzzy interpretive structural model Figure 1.

Table 5. First Level Partition

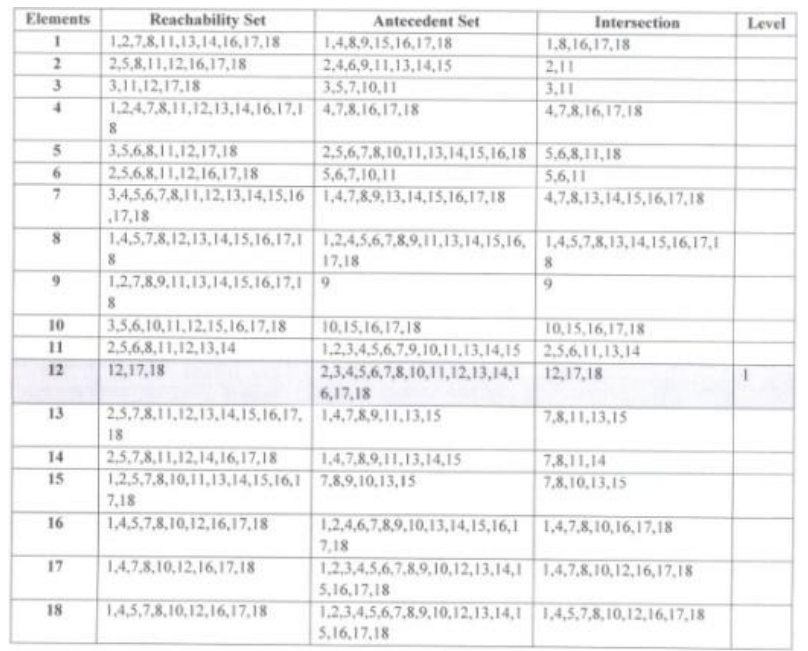


Table 6.Complete levels of the Inhibitors
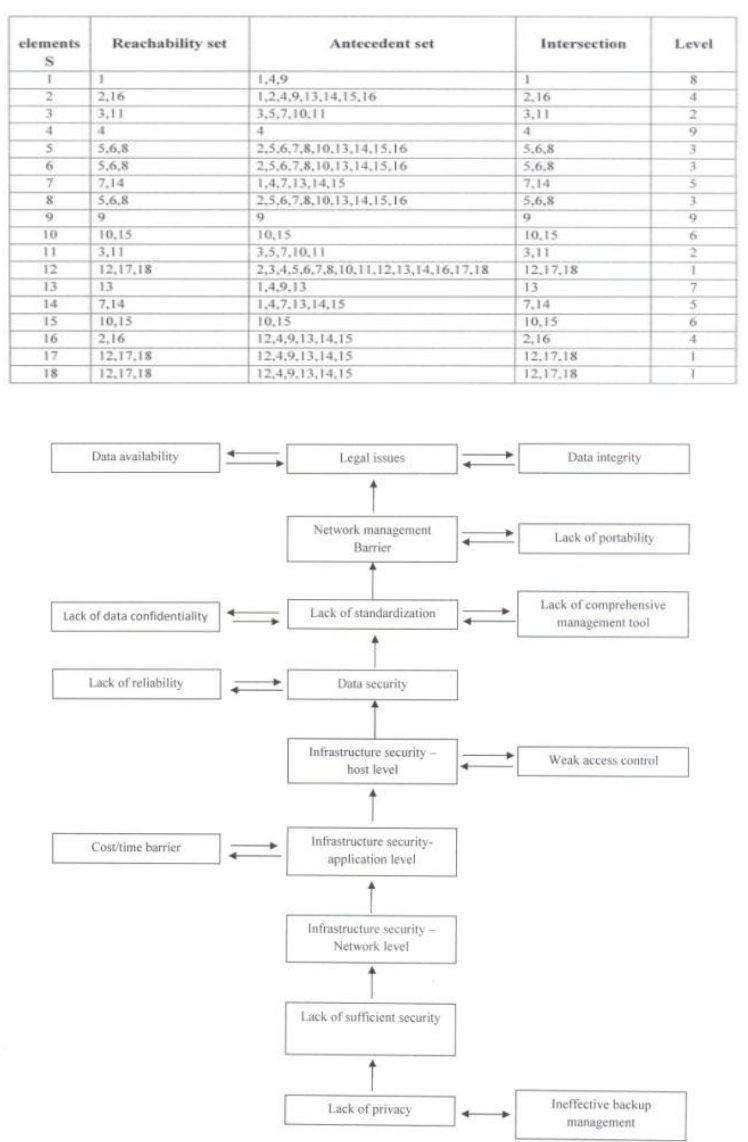

Figure 1.Fuzzy interpretive structural model

\subsubsection{Stagnation Matrix}

The row sum is taken as driving power; the column sum is taken as dependence power and is represented as $\mathrm{R} 1 \& \mathrm{C} 1$. Final reachability matrix is multiplied to a power of 2 . Here the row sum and column sum is taken as R2 \& $\mathrm{C} 2$. The process is continued, each time row sum and column sum is calculated and tabulated and is shown in Table 5.

Table 5. Stagnation Matrix for Inhibitors.

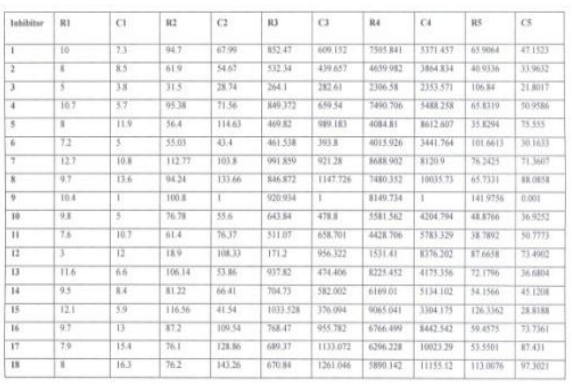

A comparison is made between R1 \&R2, R2\&R3,R3\&R4,R4\&R5,R5 \&R6 and so on until the rank of the driving $\&$ dependence power remain $s$ the same, i.e. maximum to minimum value of the driving power remains the same for the same inhibitors. The same process is repeated for the dependence power. A comparison is made between $\mathrm{C} 1 \& \mathrm{C} 2, \mathrm{C} 2 \& \mathrm{C} 3, \mathrm{C} 3 \& \mathrm{C} 4, \mathrm{C} 4 \& \mathrm{C} 5$, and $\mathrm{C} 5 \& \mathrm{C} 6$ and so on. Check for stagnation. A matrix is said to be in stagnation when the dependence power and the driving power remains the same for the same inhibitors even though matrix is multiplied to higher powers. When comparing R5 \&R6, C5 \&C6 the value remains the same So the matrix is in stagnation. For example inhibitor 1 keeping 12th position in driving power and $9^{\text {th }}$ position in dependence power. This position remains the same for further multiplication. Stagnation of the final reachability matrix is obtained to a power of 5. MATLAB function is used for plotting fuzzy ISM .A three dimensional view of fuzzy ISM is shown in Figure 2.

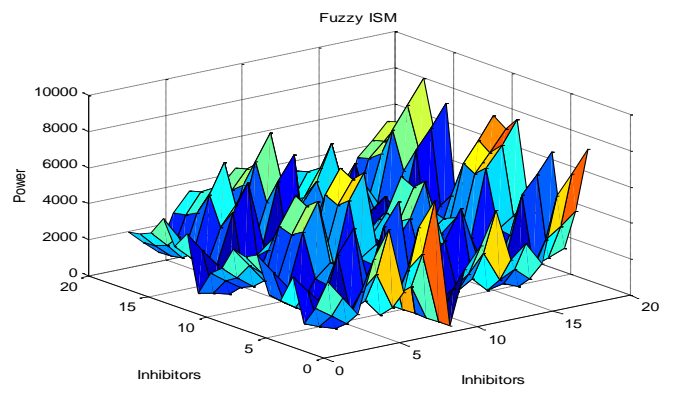

Figure 2. Fuzzy ISM

\subsection{Development of FMICMAC}

Fuzzy Matrices d' Impacts Croises Multiplication Appliquee a UN Classiment can be used for finding direct and indirect relationship among inhibitors of cloud computing. Conventional MICMAC analysis considers only binary type of relationship. Fuzzy set theory is introduced to increase the sensitivity of conventional MICMAC analysis. An additional input of possibility of interaction 0 through1 scale is introduced in fuzzy MICMAC. For fuzzy MICMAC analysis the final reachability matrix Table 2 is considered. The sum of the row is taken as driving power and sum of column is taken as dependence power. A graph is plotted taking dependence power on $\mathrm{X}$ axis and driving power on $\mathrm{Y}$ axis, [Figure3]. Based on driving power and dependence power all the inhibitors under study are classified into four categories. They are (1) Autonomous, (2) Dependent, (3) linkage, (4) Independent. It is observed from Figure 3 that the element 3 has driving power 5 and dependent power 3.8. The first cluster known as autonomous have low dependence power and low driving power. Since both the powers are weak the inhibitors are considered as weak one. Second cluster is dependent, having low driving power and high dependence power. Third cluster Linkage is having high dependence power and high driving power. Fourth cluster is Independent having high driving power and low dependence power. By making a study on above categories it is found that autonomous element i.e. the inhibitors in the autonomous region is very weak and it doesn't influence the system. So autonomous elements can even be disconnected from the system. The inhibitors under 
dependent cluster, linkage cluster and independent cluster are very important. Elements coming under second ,third and fourth cluster are strongly interrelated and its influence will changes the system as a whole

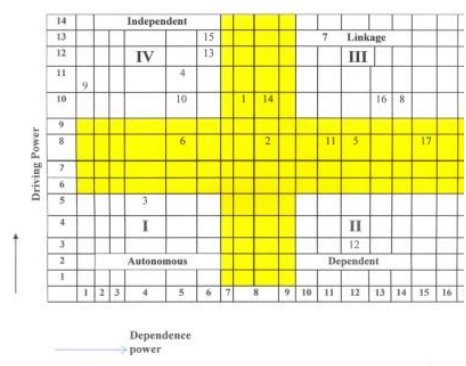

Transition Region

Figure 3.Driving Power dependence Diagram

\section{RESULTS AND DISCUSSIONS}

In the selected inhibitors the $3^{\text {rd }}$ one (lack of portability) is coming under autonomous. It is very weak so it can be eliminated. In the second cluster element 12 (legal issues) is coming under dependent. The elements $2,5,7,8,11,14,16,17$ and 18 is coming under $3^{\text {rd }}$ cluster and has to be considered as very powerful inhibitor which can affect the system. These inhibitors should be handled carefully. Elements 1, $4,6,9,10,13$ and 15 are under $4^{\text {th }}$ cluster- independent category. This will also affect the system. . In fuzzy MICMAC a "transition region" (shown in yellow color) is also considered (Pramod \&Banwet, 2012). Transition region is due to influence of fuzziness. The elements have tendency to move to nearest region. The elements in the transition region have an affinity to jump other regions. Here the elements $1,2,14$ are in the transition region. So the prediction of elements in the four clusters may vary depending on the fuzziness.

Elements having high driving power \& dependence power are the most important inhibitors (lack of privacy and ineffective backup management). Dependence power and driving power direct some valuable insight about the importance and interdependence of inhibitor within a system.

\section{CONCLUSION}

The research work pinpoints the impact of various inhibitors of cloud computing by making Fuzzy ISM analysis. Fuzzy ISM model is constructed considering partition levels . FISM model considering stagnation is generated using MATLAB. From the above models the interrelationship between the inhibitors can be identified there by necessary steps can be taken to avoid the major inhibitors. In this paper, selected eighteen elements are considered as inhibitors and proved by analysis that all the fifteen inhibitors from eighteen are important and necessary remedies should be taken to avoid it. Fuzziness among the interrelationship is studied .Cloud computing is an automated, pay as you go service through a web browser.
Flexibility of cloud computing is very high .Structural flexibility of the inhibitors is derived from a graph relating dependence power and driving power i.e. with FMICMAC analysis. The inhibitors affecting the system can be corrected so as to improve the quality of cloud computing services. Cloud service is said to be portable if we can get service among countries. Lack of portability is considered as an inhibitor and is numbered as 3 . This element is coming under autonomous i.e. having weak driving power and weak dependence power. This inhibitor can be removed from the system itself as it doesn't cause any relationship with others. This finding provides guidelines to cloud computing security issues.

\section{REFERENCES}

[1] Wang.C and Wulf W. A., "Towards a framework for security measurement", 20th National Information Systems Security Conference, Baltimore, MD, Oct. 1997, pp. 522-533.

[2] Savola.R and Abie.H, "Development of measurable security for a distributed messaging system," International Journal on Advances in Security, Vol. 2, No. 4 (2009), 2010.

[3] Jaquith. A, "Security metrics: replacing fear, uncertainty and doubt,"Addison-Wesley, 2007.

[4] Gadia.S, "Cloud computing: an auditor's perspective," ISACA Journal, Vol. 6, 2009.

[5] Gellman.R, "Privacy in the clouds: risks to privacy and confidentiality from cloud computing," World Privacy Forum (WPF) Report, Feb.23,2009.

[6] Cloud Security Alliance, "Top threats to cloudcomputing", Version 1.0. Downloaded from: www.cloudsecurityalliance.org [July 4, 2010].

[7] Sage.A, Interpretive Structural Modeling: Methodology for Large-scale Systems, 91-164. McGraw-Hill, New York, 1977.

[8] Warfield.J. Developing inter-connection matrices in structural modeling. IEEE Transactionsons on Systems, Man and Cybernetics, 2005, 4(1): 81-67.

[9] Wang.C, "Forrester: A close look at cloud computingsecurityissues,"

http://www.forrester.com/securityforum2009, 2009.

[10] IDC, "It cloud services user survey, pt.2: Top benefits \& challenges," http://blogs.idc.com/ie/?p=210, 2008.

[11] Zetta, "Zetta: Enterprise cloud storage on demand," http://www.zetta.net/, 2008.

[12] Chen.P, Lee.E, Gibson.G, Katz.R, and Patterson.D, "RAID: High performance,reliable secondary storage," ACM Computing Surveys (CSUR), vol. 26, no. 2, pp. 145-185, 1994.

[13] Yahoo!, "Hadoop distribted file system architecture," http://hadoop.apache.org/common/docs/current/hdfs design.html, 2008. 
[14] Dwork.C et al., "Differential privacy," LECTURE NOTES IN COMPUTER SCIENCE, vol. 4052, p. 1 , 2006.

[15] Dwork.C, "Differential privacy: A survey of results," Lecture Notes in Computer Science, vol. 4978, p. 1, 2008.

[16] Dean. J and Ghemawat.S, "MapReduce: simplified data processing on large clusters," in Proceedings of the 6th conference on Symposium on Opearting
Systems Design \& Implementation-Volume 6 table of contents, 2004, pp. 10-10.

[17] Bardin, J"Security Guidance for Critical Areasof Focus in Cloud Computing," www.cloudsecurityalliance.org/guidance/csaguide.pdf , 2009.

[18] Hwang, K G. Fox, and Dongarra.J, Distributed Systems and Cloud Computing: Clusters, Grids/P2P, and Internet Clouds, Morgan Kaufmann, to appear, 2010 . 